\title{
GETÚlIO VARGAS: AS VELHAS PRÁTICAS DE UM ESTADO NOVO
}

Sidnei Ferreira de Vares*

Neste ano de 2016, completam-se 52 anos do suicídio de Getúlio Vargas. Visto como um político controverso, Vargas tem lugar assegurado entre os grandes nomes da política nacional do século XX. Conhecido como "pai dos pobres", o estadista nascido na cidade de São Borja, Rio Grande do Sul, foi um dos líderes da Revolução de 1930, ascendendo à presidência da República naquele mesmo ano, e dando início à chamada "Era Vargas".

Para muitos intérpretes, esse período foi marcado por avanços econômicos e sociais, embora tutelados por práticas autoritárias, das quais, em grande medida, ainda somos herdeiros. De tal modo, é mister perguntar à guisa de provocação: por que Getúlio Vargas se tornou imprescindível para os estudos do Brasil contemporâneo? Em outros termos, por que, ainda hoje, se fala dele?

Vargas foi, indubitavelmente, um homem "acima da média", em que pesem todos os riscos que tal expressão comporta. De certo, nosso personagem reúne qualidades e defeitos, como qualquer outro ser humano. Mas o fato de ter vivido sempre no limite desses extremos, o torna um personagem "paradoxal" e, por este prisma, talvez o adjetivo "fascinante" não seja de mal empregado.

E o que se pretende demonstrar aqui? Bem, como sugere o título deste ensaio, intentamos salientar as continuidades entre as velhas práticas políticas, inerentes ao período que antecede à Revolução de 1930, no qual vigorou uma forma de "liberalismo oligárquico" assentado na força do coronelismo, e as práticas políticas levadas a cabo por Getúlio no período pós-30.

Com isso, não estamos negando as descontinuidades, sem dúvida presentes. Aliás, o emprego do termo "Revolução de 1930", que acatamos integralmente, é a notação mais clara disso. Rejeita-se, nesse sentido, a tese defendida por Edgar de Decca e Ítalo Tronca, segundo a qual não houve uma Revolução em 1930. Aproximamo-nos, sim, da interpretação de Caio Prado Júnior, Leôncio Basbaum e Nelson Werneck Sodré, para os quais o evento de 1930 constituiu uma revolução burguesa.

O que estamos defendendo aqui é que, embora a Revolução de 1930 tenha possibilitado profundas transformações no plano político, econômico e social, do ponto de vista dos avanços

Doutor e mestre em Educação pela USP. Professor dos Cursos de Filosofia, História e Pedagogia do Centro Universitário Assunção - UNIFAI. 
democráticos, o que se viu foi a reprodução da truculência tradicional, com um agravante: para além dos instrumentos de dominação usuais, centrados na repressão e na assimetria das relações entre as elites agrárias e as massas rurais, a "Era Vargas", que se desenvolve em um país mais urbanizado, foi responsável por incrementar novas formas de opressão, baseadas, sobretudo, na aplicação da violência simbólica típicas dos regimes fascistas, tal como ocorreu em parte da Europa nesse mesmo período.

No nosso modo ver, essas duas expressões da violência (física e simbólica), não só deram sustentação ao Estado Novo, como também se arraigaram enquanto prática corrente na política brasileira vindoura. Daí a afirmação inicial de que ainda somos signatários da política empreendida durante o período getulista.

Do ponto de vista das estratégias de dominação classista, vê-se claramente a continuação dos instrumentos de coerção, conquanto, na fase getulista, também seja possível avistar a adição de um ingrediente novo, que conduz a um aprimoramento das engrenagens políticas burguesas, consubstanciado no controle da grande mídia e na difusão da imagem paternalista do "pai da nação". Nacionalismo, desenvolvimentismo e centralização política convertem-se, assim, em marcas indeléveis da Era Vargas.

Vargas foi um homem de muitas qualidades. Primeiramente, dispunha de uma grande capacidade de análise conjuntural, o que, em diversas ocasiões, lhe permitiu antecipar e prever alguns desfechos. Em segundo lugar, tinha a capacidade de promover tensões e divisões entre os seus oponentes, dando sentido à máxima maquiavélica “divides e governarás”. Isto explica porque Getúlio foi durante anos a figura mais proeminente da política brasileira. Sua habilidade em manipular inimigos e aliados evidencia-se em várias ocasiões.

Vejamos algumas delas. Getúlio enfrentou duas revoluções (1930 e 1932), uma como líder, a outra como alvo de grupos dissidentes; protagonizou um governo provisório que, a despeito de qualquer sentido, durou quatro anos (1930-1934); foi eleito indiretamente presidente, em 1934; também esteve à frente de uma ditadura de caráter personalista, o Estado Novo; e, por fim, foi eleito democraticamente em 1950, voltando à presidência da república.

Do que foi posto, pode-se inferir uma terceira capacidade: a versatibilidade. Getúlio, como um político camaleão; mudava de cor conforme o ambiente. Basta lembrar que, no imediato pós-30, apoiou-se no "Clube 3 de Outubro", reduto dos tenentes. Pouco depois, após a promulgação da constituição de 1934, se amparou no movimento integralista. Durante o Estado Novo, seu esteio foram os militares de alta patente. No final do Estado Novo, porém, aproxima-se da classe 
trabalhadora, fundando inclusive um partido, o PTB, que lhe deu suporte para vencer as eleições de 1950.

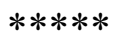

Antes de iniciarmos nossa análise sobre a Era Vargas, cumpre fazer alguns esclarecimentos. Comecemos pelo título do ensaio, "Getúlio: as velhas práticas de um Estado Novo", que pode erroneamente sugerir que nos restringiremos a analisar o período compreendido entre 1937 e 1945.

Contudo, nosso escopo analítico é bem mais largo, pois atenta-se para os 24 anos em que Getúlio Vargas esteve direta ou indiretamente no poder. Desta feita, consideramos que, enquanto projeto político, o Estado Novo teve início muito antes de 1937.

No nosso entendimento, desde sua chegada ao poder como líder da revolução de 1930, Vargas tinha a intenção de se perpetuar. Partilhava, portanto, da posição dos tenentes que o cercavam, segundo a qual a continuidade do regime liberal anterior proporcionaria o retorno do modelo coronelista, contra o qual haviam se insurgido os revolucionários.

Isto explica porque o Governo Provisório se estendeu tanto, só terminando devido aos efeitos políticos da Revolução Constitucionalista de 1932, que praticamente encurralou Getúlio, obrigado pela força das circunstâncias a marcar a data para a Assembleia Constituinte (maio de 1933).

Aliás, o levante em São Paulo foi um dos poucos erros estratégicos cometidos por Getúlio, que ao invés de indicar um paulista como interventor deste Estado, a contento do Partido Democrático - que o apoiara durante a Revolução de 1930 -, nomeou o tenente pernambucano João Alberto. Isso acabou por gerar um grande descontentamento entre os paulistas, o que resultou, inclusive, na coalizão do Partido Democrático com o Partido Republicano Paulista, inimigos históricos que se unem contra Getúlio.

Contudo, a maior prova de que o Estado Novo constituiu um projeto de longa data é o fato de que, um dia depois de instituído, em 1937, uma nova constituição elaborada pelo jurista Francisco Campos apareceu como que por milagre. Ora, seria ingênuo acreditar que "Chico ciência”, como Campos era chamado, tenha elaborado sozinho, durante uma noite de insônia, a nova constituição - jocosamente chamada de "Polaca". É bem provável que esta já estivesse pronta, o que reforça a tese de que Getúlio planejava se perpetuar no poder. 
O brasilianista Thomaz Skidmore parece ter razão ao afirmar que ao longo dos anos 30 Vargas conseguiu produzir um sentimento de descrença em relação às práticas democráticas, preparando a opinião pública para a instauração do Estado Novo. Não por acaso, não se presenciou qualquer tipo de resistência ao golpe de 1937. Em outros termos, parece que a sociedade, naquele instante reduzida à participação política das elites e das classes médias urbanas, pagou para ver o que aconteceria.

$* * * * *$

Agora sim, podemos iniciar uma reflexão mais aprofundada a respeito da tese anteriormente anunciada, a saber, de que existe uma continuidade básica entre a política dos governadores iniciada pelo governo do presidente Campos Salles e as práticas políticas inerentes ao Estado Novo, pois, em ambos os casos, presenciamos: (a) o aparelhamento do Estado, transformado em espaço dos interesses da burguesia nacional; (b) a reprodução de práticas truculentas com vistas à manutenção da ordem social; e (c) a implementação de políticas reformistas, impedindo a organização de uma frente popular.

Porém, no caso específico do período getulista, percebe-se um novo elemento, tão ou mais perverso do que aqueles consoantes às antigas formas de dominação. Trata-se, pois, da criação de uma máquina repressiva e vigilante que, ampliada em sua potencialidade, impõe-se, agora, sob um prisma ideológico.

Destarte, o Estado getulista adquire a forma mais bem acabada do Estado burguês tal como propugnado pelo autor marxista Louis Althusser: de um lado, os meios de repressão, simbolizados pela polícia, exército, sistema jurídico e prisional e, de outro, os meios ideológicos, responsáveis pela difusão dos valores e da visão de mundo tipicamente burgueses.

Conforme denunciaram Adorno e Horkheimer em sua "Dialética do Esclarecimento", a racionalidade moderna, entendida como instrumento de dominação - forjado na remota separação entre essência e aparência - revela o seu caráter mais pernicioso, cujo cume identifica-se com o surgimento dos regimes políticas totalitários na primeira metade do século XX.

Nesse sentido, a máquina política do Estado Novo, expressa a "melhor" das intenções da burguesia brasileira: a construção imagética de um patrono - Getúlio Vargas - e a anulação das massas seja pela brutalidade ou pelo convencimento. 
Ora, no que concerne ao Estado Novo, facilmente observam-se os atributos dessa engrenagem política montada por Getúlio. Instaurado mediante a ameaça do "espectro comunista", e materializado pelo General Olímpio Mourão Filho que, com seus dotes ficcionais, produziu uma das maiores farsas da história republicana - o Plano Cohen -, o Estado Novo não só significou uma resposta à articulação do PCB junto às massas, mas, igualmente, a consolidação do projeto de poder da burguesia.

Para tanto, desde o início, Getúlio se esforçou em montar uma estrutura política independente do apoio de qualquer grupo social ou político específico. Órgãos políticoadministrativos como DASP (Departamento Administrativo do Serviço Público) são a demonstração disto. Soma-se a este, os órgãos repressivos como o DEOPS (Departamento de Ordem Política e Social) e órgãos propagandísticos, como o DIP (Departamento de Imprensa e Propaganda). Ademais, podemos ainda mencionar o SNI (Serviço Nacional de Informação).

Esses órgãos contribuíram enormemente para a manutenção do projeto getulista. Alguns deles, inclusive, foram reaproveitados, com pequenas alterações, pela ditadura civil-militar instaurada em 1964. Grosso modo, pode-se afirmar que o conjunto dessas instituições emoldurou o Estado Getulista, atuando em três grandes frentes: violência, vigilância e persuasão.

A primeira delas, certamente, foi empregada com maior rigor aos opositores políticos, indo desde prisões até a tortura e assassinatos. O número de condenações políticas, de torturados e mesmo de mortos durante o Estado Novo foi bastante significativo. A segunda, por sua vez, pode ser facilmente identificada através dos arquivos do regime, hoje disponíveis, e que contêm um grande número de pessoas fichadas pelos órgãos de vigilância, em sua maioria militantes políticos, intelectuais e críticos do governo. A terceira e última dessas frentes fica por conta da propaganda e do controle da mídia. Getúlio, como poucos, soube manipular os símbolos nacionais, atrelando-os à ideia de que o país tinha um pai zeloso e protetor: ele próprio. Os mecanismos que lhe permitiram essa propagação foram variados: rádio, jornais, sistema de ensino e até mesmo as artes como o cinema, o teatro e a música. Vê-se claramente o sentido demagógico do governo getulista.

Não por acaso Getúlio concedeu algumas "benesses" à classe trabalhadora. Não por benevolência, mas, indubitavelmente, por uma questão estratégica. A partir de 1943, quando o Brasil entra na Segunda Guerra Mundial, marcando sua posição a favor dos "aliados", Getúlio pressente que seu governo estava com os dias contados. Uma nova base política, portanto, precisava ser construída. Ao lado de seu Ministro do Trabalho Marcondes Filho, Getúlio trabalhou no sentido de cooptar a classe trabalhadora, lançando um conjunto de leis trabalhistas (CLT) e alçando, 
definitivamente, seu nome na história como o "pai dos pobres". Sua estratégia, imbuída de um tom populista, mostrou-se certeira, pois não só conseguiu eleger o General Dutra em 1946, como, também, elegeu-se senador por dois Estados (São Paulo e Rio Grande do Sul). Com todo este prestígio, Getúlio ainda teve tempo para conquistar a presidência do Brasil, em 1950, pelo voto popular.

De tudo que expusemos, alguns pontos merecem ser salientados. Primeiro, a Era Vargas representou uma mudança política, visto que o "liberalismo oligárquico" da República Velha cedeu lugar, após 1930, a uma conjuntura política cada vez mais autoritária e centralizadora. Também do ponto de vista econômico e social é possível avistar transformações. A industrialização e a urbanização, respectivamente, são provas cabais disto.

Entretanto, uma visão mais oblíqua dos processos políticos aponta para a manutenção das formas de dominação usuais. A violência continuou a ser empregada abertamente contra as massas, mas, a partir do Estado Novo, é possível observar um refinamento quanto aos instrumentos de dominação, que, grosso modo, acompanharam o desenvolvimento histórico dos meios de comunicação de massas. Mais eficazes do que os instrumentos de repressão tradicionais, estes instrumentos de difusão ideológica ajudaram a gerar um sentimento positivo em torno de uma tutelação política, amputando qualquer iniciativa acerca da mobilização popular e da autonomia política.

Com certo atraso, é bem verdade, a burguesia brasileira adentra os anos de 1930 e 1940 alinhando-se definitivamente à conjuntura capitalista mundial. Segundo a famosa asserção de Karl Marx, "a classe que detém os meios de produção detém, igualmente, os meios de difusão intelectual e a produção dos valores". No caso brasileiro, a burguesia, detentora dos meios produtivos e dos meios repressivos, refina este segundo, desenvolvendo, durante o período getulista, os meios de difusão intelectual. Assim sendo, o ciclo de dominação burguesa, enfim, se completa. 